\title{
Bacteriological Indicators on the Environment and in Human Health
}

\author{
RUVALCABA LEDEZMA JESÚS CARLOS ${ }^{1 *}$, ROSAS PÉREZ IRMA², PERTUZ BELLOSO \\ SILVANA BEATRIZ1 ${ }^{1}$ INTERÍAN GÓMEZ LETICIA ${ }^{3}$ and RAYGOZA ANAYA MIGUEL ${ }^{4}$
}

\author{
${ }^{1 *}$ Research Professor (ICSA-UAEH) Institute of Health Sciences, University of the State of Hidalgo. \\ ${ }^{2}$ Research Professor at the Institute of Atmosphere Studies(UNAM) \\ National Autonomous University of Mexico. \\ ${ }^{3}$ Professor and Laboratory Technician, ( $U$ de $G$ )University of Guadalajara, Jalisco. Mexico. \\ ${ }^{4}$ Research Professor, Institute of Public Health (U de G)University of Guadalajara, Jalisco.
}

http://dx.doi.org/10.12944/CWE.9.1.14

(Received: February 15, 2014; Accepted: March 05, 2014)

\begin{abstract}
Mexico has public health problems due to its inadequate systems for sewage treatment, sanitation means and low income and economic levels, which influence the increase of disease manifestation. Determine seasonal variations, frequency and distribution of enterobacteriaairborne aerosols incoming from "San Juan de Dios" River. It is worth mentioning that, these bacteria possess antimicrobial and heavy metals resistance, such as to $\mathrm{Pb}, \mathrm{Cr}$, and $\mathrm{Cd}$, and their hemolytic profile. Therefore, an ecological study was conducted during the seasons of summer and autumn. 822 enterobacteria strains were collected, from which 723 were identified under 18 genres and 40 species, from which $63.90 \%$ corresponding to summer and $36.09 \%$ to the autumn season. As a critical sampling, point number 2 showed to have 265 colony forming units during summer and 124 during autumn. 48 strains had beta-hemolytic profile; the $68.57 \%$ of identified strains showed resistance to more than two antibiotics in reference of $\mathrm{Pb}, \mathrm{Cd}$ and $\mathrm{Cr}$ to which also showed resistance. Enter bacteriological recoverability shows values above 1×103 Gram negative/m3 of air, as risk factors for human health; which allows (due to their characteristics) their implementation as useful indicators of risk exposure.
\end{abstract}

Key words: Aerosols, Enterobacteria, Resistance, Antimicrobials, Heavy metals, Risk indicators, Environmental and wastewater.

\section{INTRODUCTION}

In Mexico, water pollution (as a public health problem) is derived from the irregular and deficient sewage system that most of the times affect low-income people, and low social and economic classes; this influences the development of health problems such as diarrhea diseases ${ }^{1}$, specialty among children who are under five years old $^{2-6}$ that is one factor that determines death in this country,2,3,4. In Mexico, one etiological agent corresponds to rota virus $(80 \%)$, and bacterial agents such as Escherichia Coli, Campylobacter
Jejuni, Salmonella sp. y Shigela $\mathrm{sp}^{5,6,7}$. However, Escherichia Coli is the most important etiological agent that is associated to wastewater contamination. This bacteria has been categorized into six serotypes ECET, EPEC, EIEC, EHEC, EAGGEC AND DAEC 2,8, 9,10. They have been related to break out enteric diseases, such as cholera or typhoid ${ }^{1}$. Wastewater has been considered as a reservoir to a great variety of microorganisms that are resistant to antibiotics and heavy metals, and b-hemolytic microorganisms are associated to virulence, between another factors such as more adherence, toxin production and invasion ${ }^{11}$, Studies 
on sewage have shown that strain gram negative were resistant to cooper (76\%), mercury (50\%), chrome $(13 \%)$, lead $(22 \%)^{12}$. Therefore, resistant strain to antibiotic such as Salmonella tiphymurimun and Escherichia coli had been detected from environmental and clinical samples of waste water ${ }^{11,13}$, we know that bacterial resistance to antibiotic can be exchanged by the conjugation of more bacteria coming from the environment ${ }^{11}$. Therefore, Louis Pasteur found the microbial contamination of air ${ }^{11}$. Today, we know that both microorganisms are accidental pollutants of air, and that air is not a habitat for microorganisms, however, this dispersed pathogenic bacteria. In the air, virulent bacteria is able to synthesize compatible solutes that support the resistance to osmotic stress from environmental increasing virulence, thus both the atmosphere inside operating rooms and pharmaceutical laboratories should to be cleaning avoiding post-surgical infections. We know that $1 \times 10^{3}$ bacillus $/ \mathrm{m}^{3}$ from air of restricted are as depict human health damage because they can be more virulent by synthesizing many proteins that allow surviving at hostile conditions with the modifications of metabolism and shape until better environmental conditions occur ${ }^{14-16}$. These conditions can be associated with both hospital and environmental clanship. However in the hospital some strains, which show antibiotic resistance, have been detected even after the cleaning, being those $E$. coli, Pseudomona Aeruginosa and Enterococcus, even had been isolated $\beta$ lactamase K. pneumonia ${ }^{22}$

The air also transports many microorganisms such as saprophytes and products of aerosolization, flagella fragments, genetic material, metabolites, volatile organic compounds, endotoxins and micotoxins. The air also contain edbio aerosols with particles between 0.5-30 micrometers of diameter. The concentration of microorganisms in bio aerosols depended on their dispensation and the deposition of particles. These conditions are associated to size, density, moisture and temperature. In this case, high environmental moisture or extreme conditions occasioned the growth of many micro organims such as fungi, bacteria, virus, and amoeba cysts provoking damage on human health due in part to inhalation, ingestion and the contact to the skin. Therefore, the human inhaled about $10 \mathrm{~m}^{3}$ of air by day, and they are can be allowed particles of 1 a 2 micrometers inside of breath provoking severe infections, asthma, pneumonia, and the others diseases that are associated to aerosols exposition ${ }^{17,18}$.

Many investigations have shown that bacteria concentration of $1 \times 10$ Gram negative bac/ $\mathrm{M}^{3}$ from environmental induced mucosal inflammatory response, such concentration is equivalent to the exposition of the $0.1 \mathrm{mg} / \mathrm{M} 3$ of enterotoxin $(26,27,28,29,34)$. In the experimental conditions one bacteria colony can grow on tryticase-soy agar in a period of 15 minutes after being exposed, which means exposure to 38 bacteria colony $/ \mathrm{m}^{3}$ as estimated for enterotoxin $/ \mathrm{m}$ from air. This study had the fundamental objective of diagnosing the biodiversity of enterobacteria found on air and sewage water by using hemolytic, antibiotic resistance and heavy metals resistance tests to predict both biological and chemical contamination and environmental and human health risk bio indicators. 36 samples from air and wastewater were employed for this research.

The aim was taking samples of biology particles from air. These conditions can depend on the biological and physical characteristics while the sample equipment on quantitative monitoring of bio aerosols such as their impact, broth media and filtration, gravity on opening agar dish, Andersen sampler, and filtration on the broth; and other tests such as microscoy, biochemistry, immunoassays and $\mathrm{PCR}^{16}$.

In Guadalajara City from Jalisco State, Mexico 14 wastewater tracks have a dual design, which means that they are closed at some point but are kept opened in most of the cases.

The most important waste water track is known as San Juan de Dios. This waste water track has suffered changes and transformation show ever its waste water hasn't received the proper treatment yet. In this point, aerosols samples were taken in order to determinate enterobacteria. What species of enterobacteria are found in the aerosols of San Juan de Dios River from Guadalajara, Jalisco State? Why this problem is still unsolved? and what is the hemolytic profile of microorganisms that show resistance to antibiotics and heavy metals such as 
$\mathrm{Pb}, \mathrm{Cd}, \mathrm{Cr}$ that cause damage on the human health of people who of downtown near of wastewater track

\section{MATERIALS AND METHODS}

\section{Study design}

An ecological study was conducted in order to investigate air quality in terms of enterobactereological biodiversity and in reference to the hemolytic profile of such microorganisms as well as their antimicrobial resistance to heavy metals such as $\mathrm{Pb}, \mathrm{Cd}$ and $\mathrm{Cr}$.

\section{Sample side}

This study aims to diagnose the quality of air in terms of its entero-bacterial biodiversity, antimicrobial and heavy metals resistance as well as their hemolytic level. It was also important to know the people's point of view about contamination of San Juan de Dios wastewater track located at the North of Guadalajara City, Mexico. The samples were taken near the downtown of Villas de San Juan at the peripheral road and a total six samples at the month by duplicating three points along the topography of the place. The point 1. Located near San Juan neighborhood. This place is opened up to Rancho Nuevo neighborhood and Santa Elena de la Cruz, El Paso without turbulence of forming water reservoirs. The point 2. Located near both Rancho Nuevo and San Juan. This place was characterized by the secondary joint cannel "Canal de San Juan" with the inclination of a waterfall that provokes both turbulence and aerosols. The point 3. Located near San Juan Neighborhood to the borderline with less turbulence than in the second point. The samples were taken during summer and autumn every Monday at the same time and at three different points on the Trypti case Soy agar by 15 minutes. The samples and controls were moved to The Microbial Ecology Laboratory and they were incubated at $37^{\circ} \mathrm{C}$ during 24 hours. Then, the bacterial growth was quantified using to Colony forming plaques. This colony was isolated on a plaque as follow.

1. The colony delimited was isolated to avoid contamination.

2. The colony with Gram negative bacilli, and the carbohydrates fermentative was selected.

3. The strain of enterobacterial resistance to both antibiotic and $\mathrm{Pb}, \mathrm{Cm}, \mathrm{Cr}$ heavy metals with the hemolytic profile was selected by high impact at the human health.

\section{Identification of Enterobacterial Strain}

The enterobacterial strain was cataloged using biochemistry smples on the Lisine and Iron agar, Simons Citrate, Ornitine Indolmovility, Mannitol, Urea agar, Sucrose, and MR-Vp following Bergey's Manual Determinative Bacteriology- 9 a, and the Gamelaya software developing to the Epidemiology and Cybernetic Laboratory of Gamelaya Institute from Russian Academic of Medical Sciences of Moscu.

\section{Hemolysis tests}

The bacteria hemolysis was evaluated by using blood on agar following standard methods, and being incubated on the template for 14 strains by sterile conditions during 24 hours at the $37^{\circ} \mathrm{C}$. The clear zone around colony was considered as positive test for hemolysis ${ }^{11}$.

\section{Resistance to Antibiotic test}

The bacteria was incubated on the MullerHilton agar $(\mathrm{pH} 7.4)$ at $4{ }^{\circ} \mathrm{C}$ using sterile swabs keep out 3 min and then put on disc and the plaque were incubated at $37^{\circ} \mathrm{C}$ during 18 hours. They culture with the resistance presented clear zone around colony. The resistance to antibiotic was cataloged as high, intermediate, and sensitive.

\section{Resistance to Heavy metals test}

Each metal was diluted by part/millions of $\mathrm{Pb}, \mathrm{Cd}, \mathrm{Cr}$, and the concentration used to $\mathrm{Pb}$ was 207 ppm, 2. 20.7 ppm, 2.7 ppm, 0.207 ppm, 0.027 ppm, $2.7 \times 10-3$ ppm, 2.07×10-4 ppm, 2.07×10-5 ppm, 2.07-6 ppm, $2.07 \times 10-7$ on the tryticase soy broth. Each concentration was incubated with the $100 \mathrm{im}$ of bacteria culture. Alike, the concentration used to $\mathrm{Cd}$ was $12 \mathrm{ppm}, 11.2 \mathrm{ppm}, 1.12 \mathrm{ppm}$, $0.112 \mathrm{ppm}, 1.12 \times 10-3 \mathrm{ppm}, 1.12 \times 10-4 \mathrm{ppm}$, 1.12×10-5ppm, $1.12 \times 10-6 \mathrm{ppm}, 1.12 \times 10-7 \mathrm{ppm}$ on the tryticase soy broth. Each concentration was incubated with the $100 \mathrm{im}$ of bacteria culture during 24 hours at $37^{\circ} \mathrm{C}$. Alike, the concentration used to Cr was 104ppm, 10.4ppm, 1.04ppm, 0.0104ppm, $1.04 \times 10-3 p p m, 1.04 \times 10-5$ ppm, $1.04 \times 10-7$ ppm, $0.104 \mathrm{ppm}, 1.04 \times 10-4 \mathrm{ppm}, 1.04 \times 10-6 \mathrm{ppm}$ on the tryticase soy broth. Each concentration was 
incubated with the 100 ìm of bacteria culture during 24 hours at $37^{\circ} \mathrm{C}$.

\section{RESULTS}

Ours results showed significative different between Colony Forming Unit and the sampling place $(p=0.010075)$, according to Kruskal Wallins Test. We also found significative different between Enterobacteria group and the sampling place $(p=0.034885)$, with the break point in the sampling place no. 2 during summer than autumn without meaningful different $(p=0.096408)$. However, the number of Colony Forming Unit presented increased at the summer (Table 1). The sampling point no. 1 was selected with 89 Colony Forming Unit of Enterobacteria, and a mean of the 15 Colony Forming Unit of Enterobacteria at summer and a mean of the 125 Colony Forming Unit of Enterobacteria. In the sampling point no. 2 presented a break point with the 265 Colony Forming Unit of Enterobacteria and the mean of 44 Colony Forming Unit of Enterobacteria at the summer. At the autumn, the Colony Forming Unit of Enterobacteria was 21 and the point 3 was detected 116 Colony Forming Unit of Enterobacteria with the mean 19 Colony Forming Unit of Enterobacteria at summer and Colony Forming Unit of Enterobacteria was 103 with mean of 17 at the autumn (Figure 1). We identified 723 strain of enterobacteria with a mean 462 Colony Forming Unit of Enterobacteria at the summer and a mean of 261 Colony Forming Unit of Enterobacteria at the autumn belong 18 genres and 40 species (Table 1 ). They had beta hemolytic proprieties with 48 strains belong 13 genrs and 20 species both seasonal summer with the 39 and 9 autumn (Table 2). They had resistance to antibiotic with 24 strains resistance to antibiotic $(68,57 \%)$ according to antibiogram test conducted on 35 strains. Theses enterobacterial had different spectrum of resistance to antibiotic, thus one strain was resistance to two antibiotics $(2.85 \%)$, and three strains were resistance to one antibiotic (8.57\%). Salmonella I strain was resistance to 12 antibiotics. Some strains showed sensitiveness to 12 antibiotics (20.0\%), (Table 3).

The strains isolated showed resistance to Nitro furantoine (71.0\%), Pefloxacine $(60.0 \%)$, Amikacine (48.5\%), Cloranfenicol (42.8\%), Carbeniciline (40.0\%), Ampicilin (37.1\%), Cefotaxima (25.7\%), Netilmicine (25.7\%), y Trimetoprim-Sulfametoxazol (8.5\%), (Figure 2). The strains resistance to antibiotics were Enterobacter cloacae, Edwarsiellaictaluri, Samonellaparatyphi and serotype I Salmonella, and Rahnellaacuatilis was resistance to pefloxacine.

The resistance to heavy metals as $\mathrm{Pb}, \mathrm{Cd}$ and $\mathrm{Cr}$ was identified on 32 strains. A $9.3 \%$ of strains were resistance to $\mathrm{Pb}$, they were growth to 207 ppm concentration of heavy metal, and another bacteria growth to $20.7 \mathrm{ppm}$ of metal (90.6\%). 15.6\% of strains were resistance to $\mathrm{Cd}$ and they were growth to $112 \mathrm{ppm}$ concentration of metal, and 21 strains growth to $11.2 \mathrm{ppm}$ concentration of metal $(65.6 \%)$. The resistance to heavy metals were also minor to some strains, thus they were growth to 0.0112 ppm of heavy metals concentration (3.12 ppm), and another bacteria growth minor concentration of heavy metals $(6.25 \%)$, and three

Table 1: Frequency and average CFU of microorganisms detected per sampling point

\begin{tabular}{|c|c|c|c|}
\hline $\begin{array}{l}\text { Stations of } \\
\text { theyear }\end{array}$ & $\begin{array}{l}\text { Sampling } \\
\text { point } 1\end{array}$ & $\begin{array}{l}\text { Sampling } \\
\text { Point } 2\end{array}$ & $\begin{array}{l}\text { Sampling } \\
\text { point } 3\end{array}$ \\
\hline Summer & $\begin{array}{l}675 \text { CFU } \\
\mu=113 \text { CFU }\end{array}$ & $\begin{array}{l}3892 \text { CFU } \\
\mu=648 \text { CFU }\end{array}$ & $\begin{array}{l}679 \text { CFU } \\
\mu=113 \text { CFU }\end{array}$ \\
\hline Fall & $\begin{array}{l}448 \text { CFU } \\
\mu=75 \text { CFU }\end{array}$ & $\begin{array}{l}1574 \text { CFU } \\
\mu=262 \text { CFU }\end{array}$ & $\begin{array}{l}623 \text { CFU } \\
\mu=262 \text { CFU }\end{array}$ \\
\hline $\begin{array}{l}\text { Hypothesis test } \\
\text { Kruskal Wallis }\end{array}$ & $\mathrm{p}=0.010075$ & $\begin{array}{l}\mathrm{p}=>0.05 \text { Point } 2 \text {. } \\
\text { resulted the most critical }\end{array}$ & $\begin{array}{l}\text { By station no meaningful } \\
\text { difference was } \\
\text { detected } p=0.096408\end{array}$ \\
\hline
\end{tabular}

Source: Direct Aerosol Samplingsewage canal Rio San Juan de Dios, Guadalajara Jalisco, Mexico 
strains $(9.3 \%)$ could not grow in the concentration of heavy metals, and they were cataloged as sensitive to them 28 strains were resistance to $\mathrm{Cr}$ and they were growth to $10.4 \mathrm{ppm}(87.5 \%)$ of concentration of heavy metal, or they were growth to $1.04 \mathrm{ppm}(3.12 \%)$, and some bacteria were not resistance to heavy metal (Table 4).

\section{DISCUSSIÓN}

Seasonal variation, regarding the microbial concentration in the environment is

Table 2: Frequency and percentege of Enterobacteriaceae detected and identified by biochemical tests

\begin{tabular}{lcc}
\hline Station of summer & 462 & 64 \\
Station of fall & 261 & 36 \\
total & 723 & 100 \\
\hline
\end{tabular}

Source: Direct Aerosol Samplingsewage of the "San Juan de Dios" River, Guadalajara Jalisco, Mexico determined by the own factors of each of the seasons. In this way, we could make reference to global climate changes expressed though the modification of the average temperature as well as the force and orientation of winds, as well as the growth and development of typical endemic plants ${ }^{14}$.

Bacterial findings collected through air sampling and study were directly associated to the aerosols which are generated from sewage water, whose sanitarian design also influences in a meaningful way, due to the particularities that the cannel represents, there are sectors that are irregular in their topography. These differences in their construction are more prominent particularly in sampling point 2, which has a cascading decline and the binding of a secondary channel for the same; this is where they had the highest number of microorganisms which significantly exceeds $1 \times 103$ bacilli Gram negative/M3 that determines the start of the presentation of adverse effects to human health. Moreover, at points 2 during the summer and autumn, this limit was exceeded but to a lesser extent in a seasonal way.

Table 3: Antimicrobial resistance of $\mathbf{3 5}$ strains to which they applied the antibiogram

\begin{tabular}{lcc}
\hline Strains & Frequency & Percentage \\
\hline Resistant to more than two antimicrobial & 24 & 68.57 \\
Withtwoantimicrobialresistance & 1 & 2.85 \\
Withresistance to antibiotics & 3 & 8.57 \\
Note: these Salmonella strains resistant to 12 antibiotics & 1 & 2.85 \\
Withsensitivity to 12 antibiotics & 7 & 20 \\
\hline
\end{tabular}

Source: Direct Aerosol Samplingsewage of the "San Juan de Dios" River, Guadalajara Jalisco, Mexico

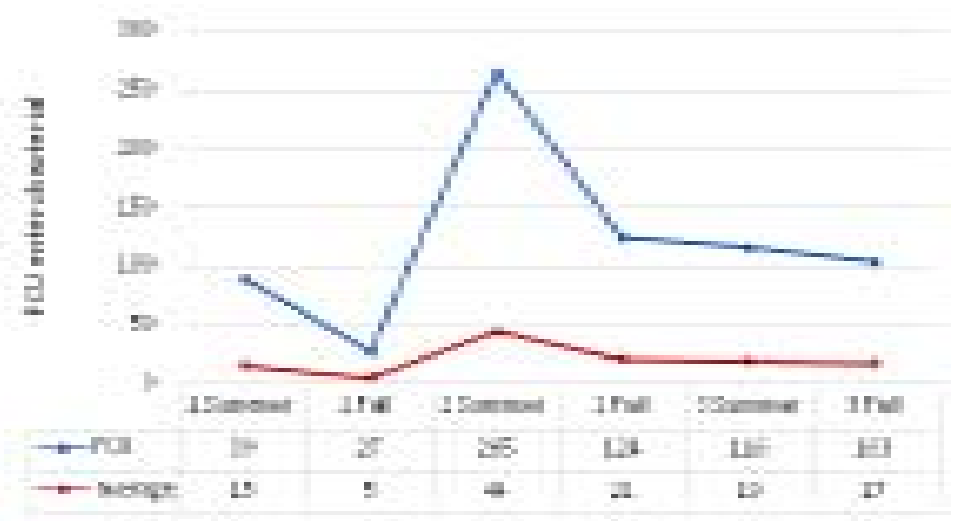

Source: Direct Aerosol Samplingsewage of the "San Juan de Dios" River, Guadalajara Jalisco, Mexico

Fig. 1: Enterobacterial and average frequency detected per sampling point 
It is worth mentioning that, during summer much more enterobacteria were identified, whose biodiversity is an important advantage for practical use, and that can be used as biological indicators of environmental pollution because, by the nature of their habitat in the human gut, or other animals, as well as the respiratory tract, represent in person the continuing cyclical interaction in the health and environment management of their own waste products that are generated from the corresponding physiological actions, but which, however, impact the stability as the current sewage waters which have become the old "San Juan de Dios "River, as a natural reservoir whose cause, partially covered, passes through densely populated areas of the city of Guadalajara Jalisco Mexico (Table 1).
Moreover, one of the most highlighted of the present research is the findings about bacteria such as Rahnella Acuatillis whose particular niche is water. However, those bacteria were isolated from aerosols generated by wastewater and which as part of their phenotypic profile, their synthetic capacity of enzymes beta-hemolytic is highlighted, as well as its edema of high resistance to heavy metals like $\mathrm{Pb}$ to 207ppm, Cd to $112 \mathrm{ppm}, \mathrm{Cr}$ to 104 ppm and their resistance to PEF, besides the presence of Escherichia Blattae whose normal niche constitutes the intestinal track of cockroaches and in whose strain beta hemolytic capacity was found, besides the presence of Salmonella biotype 1 with an hemolytic profile and a multiple resistance to 12 antimicrobial.

Table 4: FCU Heavy metal resistant ppm $\mathrm{Pb}, \mathrm{Cd}$ and $\mathrm{Cr}$

\begin{tabular}{lccccccc}
\hline $\begin{array}{l}\text { Frequency of } \\
\text { strains }\end{array}$ & Tubo & Pb/ppm & $\%$ & Cd/ppm & $\%$ & Cr/ppm & $\%$ \\
\hline 23 & 2 & 20.7 & 90.6 & & & & \\
3 & 1 & 207 & 9.3 & & & & \\
21 & 2 & & & 11.2 & 65.6 & & \\
5 & 1 & & & 112 & 15.6 & & \\
3 & 0 & & & sensitive & 9.3 & & \\
2 & 4 & & & 0.112 & 6.25 & & \\
1 & 5 & & & 0.0112 & 3.12 & & \\
28 & 2 & & & & & 10.4 & 87.5 \\
1 & 3 & & & & & sensitive & 9.3 \\
3 & 0 & & & & & & \\
\hline
\end{tabular}

Source: Direct Aerosol Samplingsewage of the "San Juan de Dios" River, Guadalajara Jalisco, Mexico

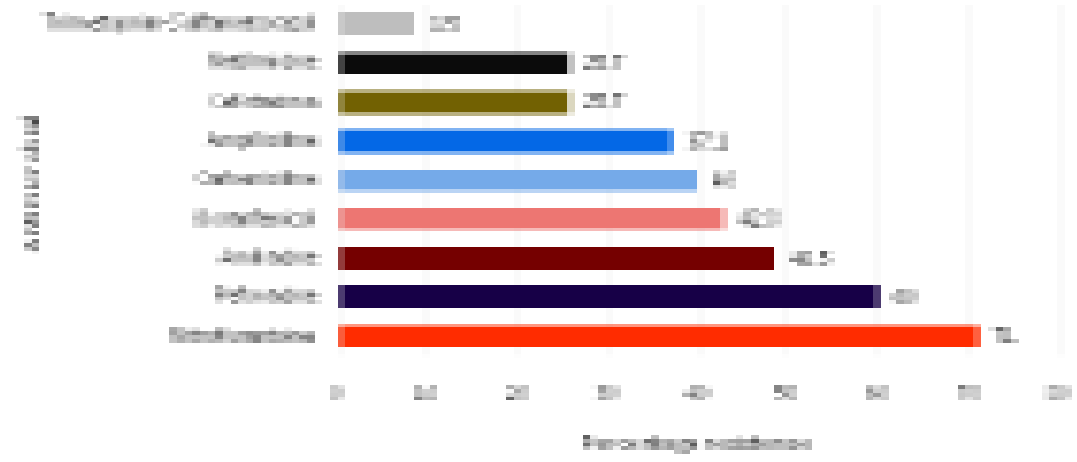

Source: Direct Aerosol Sampling sewage of the "San Juan de Dios" River, Guadalajara Jalisco, MexicoNote: Among the multiresistant strains were found Entrobacter cloacae, Edwarsiellaictaluri, Salmonella paratyphi and Salmonella biotype I, resulted Rahnellaacuatilispefloxacin resistant.

Fig. 2: Antimicrobials the studied strains showed higher resistance antibiogram. 
Finally the ecological-environmental meaningful findings of multiple airborne bacterial species that presents high resistance to heavy metals is also meaningful because apart from their presence in the air is considered as biological indicators of environmental pollution.

At the same time, they also acquire additional usage value in order to function as bioindicators of chemical pollution. This, under the dynamic interaction that is maintained in its environment, under extreme conditions, as are the industrial wastes that contain metallic residues which stimulate the environmental typical micro flora that acquires high resistance levels towards the same as part of a natural response to their adaptation and ulterior survival in the aerosols generated from the waste water and which allow to regulate their own virulence factors $(21,22,23)$, having an impact on the manifestation of health risks of inhabitants who live nearby these type of environments.

The speech employed by the interviewees reflects for instance, the meaning of pollution associated with environmental conditions present in their community, which indicates that one must pay attention to this type of problems that show the causes of the problems to a public health level in which it is necessary to work focusing on sanitization problems from an environmental methodology, trying to find the control or elimination of risks associated to environmental conditions, which if we remember have an impact on the virulence of bacteria as well as on human health ${ }^{22}$. The Evolution of Yersinia pestis of speciation from an environmental, non-pathogenic ancestor is a good example of the evolution steps that are involved in the emergence of bacterial pathogens. This process began with the acquisition of the plasmid pCD1 by environmental Yersinia.This process is fully explained Wren (2003), Keim and Wagner $(2009)^{23}$ hence the importance of living in a healthy environment, not laden bioaerosols contaminated with Enterobacteriaceae.

The air transport of virulent microbiological agents, as well as the density of antibiotics and resistant bacteria may enhance the adverse effects on public health and environmental surroundings, hence the importance of considering the implementation of inter hospital epidemiology And at the community level by exposure of virulent organisms, as they impact on human health in the family economy and health care.

\section{CONCLUSIONS}

1. It is feasible to recover enteric microorganisms in aerosols generated from sewage, through the methodology employed in this study.

2. During the summer season, a high quantity and biodiversity of enteric strains was identified, particularly at the second sampling point.

3. The estimated concentration was higher than $1 \times 103 / M 3$, besides classical strains and the virulence factors identified, which suggests there is a social-ecological relationship with the inhabitants of neighboring communities to sewage waters.

4. There is a relationship between the "topographic" design sewage and the amount of airborne Enterobacteria.

5. The presence and characteristics of resistance to antibiotics and heavy metals in some enterobacteria strains allows us to propose them as bio-indicators of environmental, microbiological, chemical pollution and as indicators of risk to human health.

\section{ACKNOWLEDGEMENTS}

The authors of the present research article would like to acknowledge and truly thank the collaboration of Yesenia Elizabeth Ruvalcaba Cobián who has a B.A in Teaching English as a Foreign Language, for her contributions on the revision and translation of the article; situation which allows the possibility to increase the transferring and modification of scientific knowledge. The authors declare that no conflict of interests for the publication of this research paper. 


\section{REFERENCES}

1. Gonzalo Gutiérrez. The National Program to Control Diarrheal Diseases: its impact on health and health services; Salud Publica Mex. 36(2):127-128 (1994).

2. Kirchner M, Abuoun M, Mafura M, ET AL. Cefotaxime Resistant Escherichia coli Collected from a Healthy Volunteer; Characterisation and the Effect of Plasmid Loss. PLOS ONE, 8: 1-8 (2013).

3. Ajami N.J., Kavanagh O.V., Ramani S. ET AL. Seroepidemiology of norovirusassociated travelers' diarrhea. Journal of Travel Medicine 21: 6-11 (2014).

4. Levine M, Ferreccio C, Prado V, et al. Epidemiologic studies of Escherichia coli diarrheal infections in a low socioeconomic level peri-urban community in Santiago, Chile. Am J Epidemiol, 138: 849-69 (1993).

5. Dekate P., Jayashree M., and Singhi S.C. Management of acute diarrhea in emergency room. Indian J Pediatr 80: 235-246 (2013).

6. Ansari S., Sherchand J.B., Parajuli K. et al. Bacterial etiology of acute diarrhea in children under five years of age.J Nepal Health Res Counc 10: 218-223 (2012).

7. Larrosa-Haro A., Macias-Rosales R., Sánchez-Ramírez C.A., ET AL. Seasonal variation of entero pathogens in infants and preschoolers with acute diarrhea in western Mexico. J Pediatr Gastro enterol Nutr, 51: 534-536 (2010).

8. Matthew A. Croxen and B. Brett Finlay. Molecular mechanisms of Escherichia coli pathogenicity. Nature Reviews Microbiol 8: 26-38 (2010).

9. James B. Kaper, James P. Nataro and Harry L. T. Mobley. Pathogenic Escherichia Coli Nature Reviews Microbiol, 2: 123-140 (2004).

10. Donnen berg and Kaper J.B. Enteropathogenic Escherichia coli. Infect Immun 60 (10): 3953-3961 (1992).

11. Amábile-Cuevas $C$. Antibiotic resistance in Mexico: a brief overview of the current status and its causes. J Infect Dev Ctries 4: 126131 (2010).
12. Lighthart B, Shaffer BT. Airborne Bacteria in the Atmospheric Surface Layer: Temporal Distribution above a Grass Seed Field. Appl Environ Microbiol. 61(4): 1492-6 (1995).

13. Olorunmola FO, Kolawole DO, Lamikanra A. Antibiotic resistance and virulence properties in Escherichia coli strains from cases of urinary tract infections. Afr $\mathrm{J}$ Infect Dis. 7(1): 1-7 (2013).

14. Kruse $H$, Sørum $H$. Transfer of multiple drug resistance plasmids between bacteria of diverse origins in natural microenvironments. Appl Environ Microbiol. 60(11): 4015-21 (1994).

15. Wolman A. El medio ambiente y las enfermedades. Boletín de Oficina Sanitaria Panamericana, 81(5): 455-461 (1976).

16. Rosas I. A. Yela y C. Santos-Burgoa. Occurrence of airborn enteric bacteria in Mexico City. Aerobiología, 10(1); 39-45 (1994).

17. WalterS.D.The Ecologic Method in the Study of Environmental Health. I. Overview of the Method. Environmental health Perspectives, 94: 61-65 (1991).

18. Walter SD. The ecologic method in the study of environmental health. II. Methodologies ues and feasibility. Environ Health Perspect. 94: 67-73 (1991).

19. Stewart SL, Grinshpun SA, Willeke K, Terzieva S, Ulevicius V, Donnelly J. . Effect of impact stress on microbial recovery on an agar surface. Appl Environ Microbiol. 61(4): 1232-9 (1995).

20. Roszak DB, Colwell RR. Survival strategies of bacteria in the natural environment. Microbiol Rev. 51(3): 365-79 (1987).

21. Cornejo-Juárez P., Velásquez-Acosta C., Sandoval S., Gordillo P., ET AL. Antimicrobial resistance patterns of isolates from urine cultures at an oncological center. Salud Publica de Mex. 49: 330-336 (2007).

22. Navarro-Navarro M., Robles-Zepeda R.E., Garibay-Escobar A., Ruiz-Bustos E. Hospital and community-acquired b-lactamasasproducing Escherichia coli and 
Klebsiellapneumoniae at hospitals in Hermosillo Sonora. Salud Pública de México. 53: 341-344 (2011).
23. Martínez JL. Bacterial pathogens: from natural ecosystems to human hosts. Environ Microbiol. 15(2):325-33 (2013). doi: 10.1111/ j.1462-2920.2012.02837 